\title{
Architectural Technology Strategies of Zero Energy Solar House
}

\author{
Ding Ding, Chongjie Wang \\ Shandong Jianzhu University; Key Laboratory of Renewable Energy Utilization Technology in Building of National Education \\ Ministry; Key Laboratory of Building Energy Saving Technology of Shandong Province, Jinan, China \\ Email: ding7777ding@foxmail.com
}

Received January, 2013

\begin{abstract}
Taking I-Magic Cube - the entry of Shandong Jianzhu University for Solar Decathlon 2013 - for example, the paper analyzes the conceptual, technological, functional and aesthetic solutions of zero energy solar house coping with ecological, economic, social and cultural challenges. Passive strategies, the solar thermal and PV system, and the building integrated solar system tactics are elaborated. Finally, industrialization and marketing viability of the solar house prototypes are discussed.
\end{abstract}

Keywords: Zero Energy; Solar Decathlon; House; Architectural Technology; Industrialization

\section{Introduction}

I-Magic Cube, the entry of Shandong Jianzhu University for Solar Decathlon 2013, is an exploring zero energy solar house. Solar Decathlon or SD which is called the Olympic competition of solar energy is the highest competition of solar energy in the world. [1]Solar Decathlon China 2013 which will be held in Datong, Shanxi Province is one of the ECP projects signed when President $\mathrm{Hu}$ Jintao visiting USA in 2011. The competition is hosted by National Energy Administration \& DOE and is undertaken by Peking University. In the competition, universities from all over the world will design and build a self-sufficient, grid-connected house, using solar energy as the only energy source and equipped with high technologies that permit maximum energy efficiency.

\section{Design Concept}

Be named I-Magic Cube, the house has two main characteristics that it is highly prefabricated and flexible.

It is prefabricated that the main building of the house is preprocessed in factory and be easily put together after transported to the lot. This strategy could improve the construction speed and reduce building pollution. At the same time, prefabrication is good for market promotion thanks to its production rate.

Modularization enables the house possible to create more reconfigurable modeling and space. PV panels fixed above the roof can be adjusted automatically ac-

${ }^{*}$ Analysis of I-Magic Cube cording to the sun angle. In addition to meet the needs of family or office life and consider the limited area of the building, parts of the furniture used variable design methods.

Modularization enables the house possible to create more reconfigurable modeling and space. PV panels fixed above the roof can be adjusted automatically according to the sun angle. In addition to meet the needs of family or office life and consider the limited area of the building, parts of the furniture used variable design methods.

\section{Passive Solar Building Design Strategies}

To build a high-efficient and economical solar building, one needs to take full use of passive design methods at first.

\subsection{Plane Layout}

Compact construction figure will reduce surface heat loss. It is good for industrialized production and transportation. Therefore, the main building of I-Magic Cube is looked like a rectangle. However, square body is a bit mechanical and is not easy to address building features. Based on the above considerations, a corridor is put to be perpendicular to the main building, which makes the house an L-type construction (Figure 1).

\subsection{Spatial Organization}

The increase of energy consumption for interior heating 
and cooling caused by artificial illumination and mechanical ventilation is a significant factor of zero energy house design.[2]Owning to I-Magic Cube's regular block, its natural ventilation and lighting situation is relatively optimistic. Shandong Jianzhu University uses simulation software like DEST, CFD, ECOTECT to further optimize the design.

\subsection{Envelop Enclosure}

Energy conservation situation of one building is directly determined by the performance of its envelop enclosure. I-Magic Cube has six carefully designed external surfaces.

FrameCAD supporting system (Figure 2) is the major structure of the house. $120 \mathrm{~mm}$ thick PU cold storage panels (Figure 3) are fastened to the steel structure. Its exterior steel thickness is $0.60 \mathrm{~mm}$, while the interior is $0.50 \mathrm{~mm}$. Thermal conductivity of the wall is 0.192 $\mathrm{W} / \mathrm{m}^{2} \mathrm{~K}$ and the noise reduction performance is $25 \mathrm{~dB}$. Mineral wool has been filled in the interspace of $\mathrm{Fra}$ $m e C A D$ to improve thermal insulation.

The competition rules that teams would not excavate the building site. Therefore I-Magic Cube is supported by steel braces. In order to guarantee energy saving property, heat transfer performance of the floor has been taken into special consideration. I-Magic Cube adopts $20 \mathrm{~mm}$ thick fiber cement board covered by $120 \mathrm{~mm}$ thick PU cold storage panel as its floor material. (Figure 4)

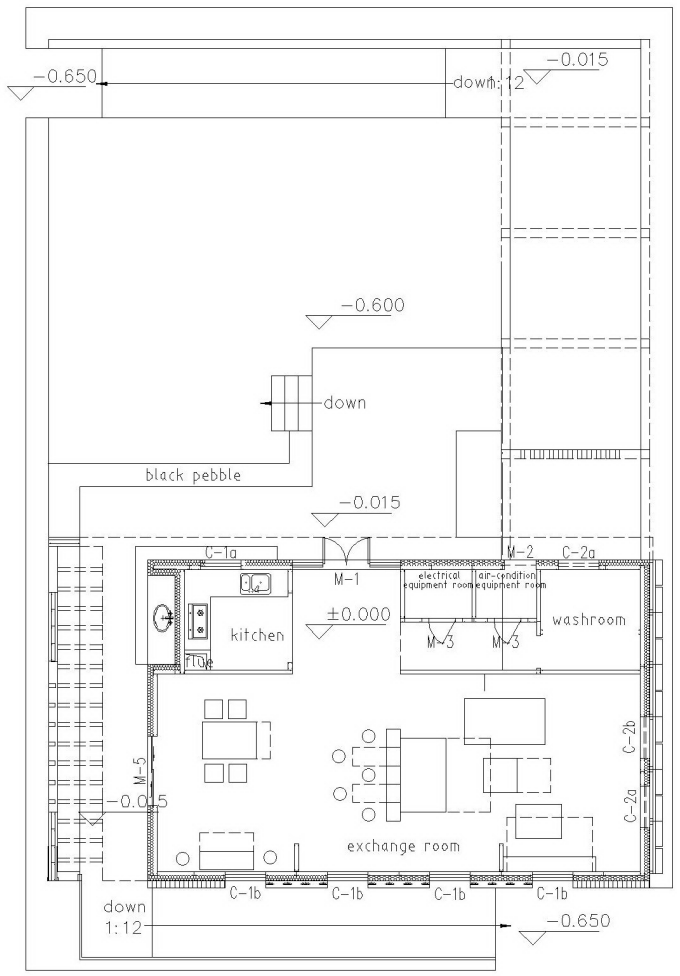

Figure 1. Floor plan.
The design takes Aluminum-clad solid wood windows, using $(4 \mathrm{~mm}+0.2 \mathrm{~V}+4 \mathrm{~mm})+12 \mathrm{~A}+6 \mathrm{~mm}$ Low-E vacuum glass and $5 \mathrm{mmG}+12 \mathrm{~A}+5 \mathrm{mmG}$ hollow toughened glass. Some windows were equipped with wind and rain sensors which could open and close the windows automatically according to weather conditions, as well as the outside roller blind system which could be adjusted according to the situation of sunshine shade.

Vertical greening is added onto south wall, east wall and the roof to improve heat-insulating property and to beauty the environment (Figure 5). There are 15 cuneiform green bags with series kinds of vegetation on the

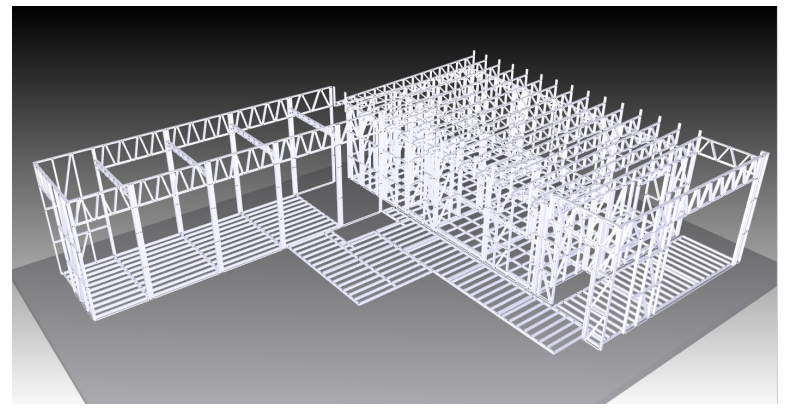

Figure 2. FrameCAD supporting system.
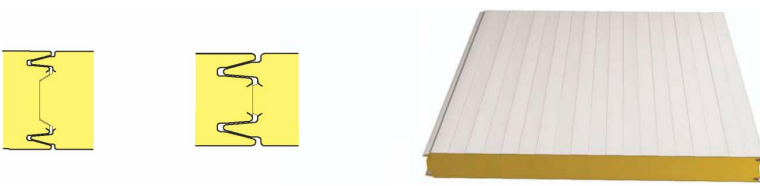

Figure 3. PU cold storage panel.

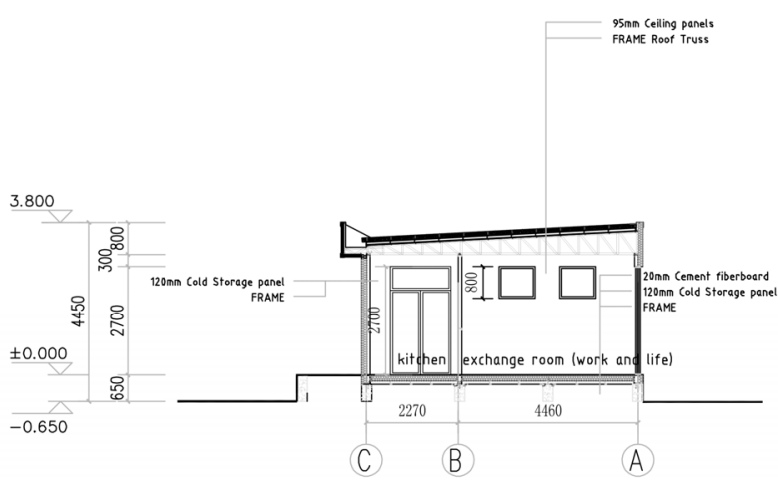

Figure 4. Section of the main building.

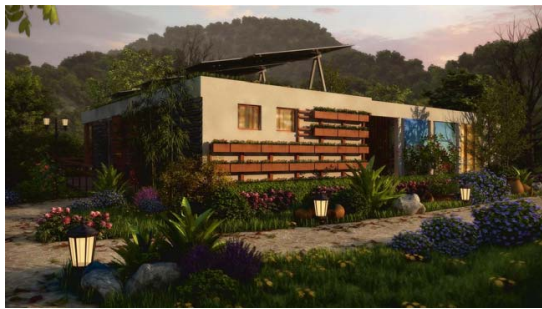

Figure 5. Rendering of vertical greening. 
south wall (Figure 6). Planting system on the eastern elevation include supporting bodies and implants. Implant is isolated from supporting body, which makes it possible to be taken and put flexibly according to need. (Figure 7) Roof greening is made up of varies grass pallets which could pave specified graphics on request. Each device of the vertical greening has its own water and fertilizer system. The plants are easily to survive.

\section{Active Solar Building Design Strategies}

The orientation of SD competition is to design and promote zero energy solar houses which are becoming the development tendency of architecture. European Parliament raised a claim in 2009 that all new buildings must be up to the standard of zero energy since 2019. [3] To achieve this goal, except for passive design strategies, designers have to use active strategies as well. In addition, adopting grid-connected technology and choosing energy-efficient appliances is a significant way to optimize the design.

\subsection{Solar Thermal System}

I-Magic Cube uses evacuated tube water heater and fresh air ventilation system to recovery waste heat. The house provides energy for air-conditioning system and cooling

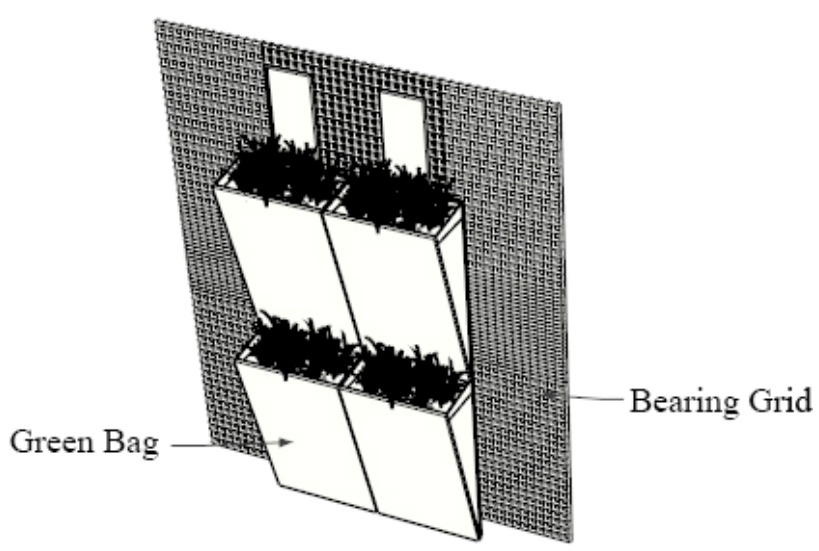

Figure 6. Vertical greening on south wall.

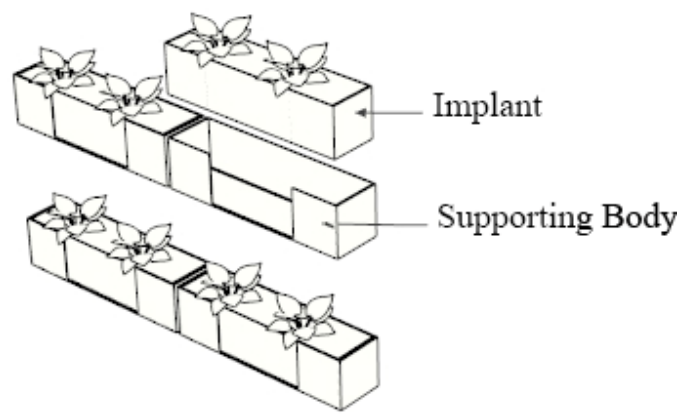

Figure 7. Vertical greening on east wall.
PV system by collecting heat from the process of power generation. It is heated by floor radiation and is cooled by air source heat pump as well as capillary system within roof and walls. The building also has solar fresh air system, using solar energy to heat air and decrease relative humidity directly. The system provides the room dry heating installation and fresh air.

\subsection{Solar PV System}

The competition has make use of grid technology since 2009. Hard-wired battery and large plug-in uninterruptable power supplies are not permitted in SD 2013. I-Magic Cube employs silicon PV panels. Located on the room, the PV system is able to track sun to improve efficiency of solar energy collection. (Figure 8)

\subsection{Building Integrated with Solar Systems}

I-Magic Cube regards PV panels, evacuated tubes and other new materials as building elements deliberately. Sun-tracking PV panels on the roof enrich architectural appearance. Evacuated tubes on the corridor create unique lighting effect. While solar fresh air thermal collectors on south wall bring the building great skin texture. (Figure 9)

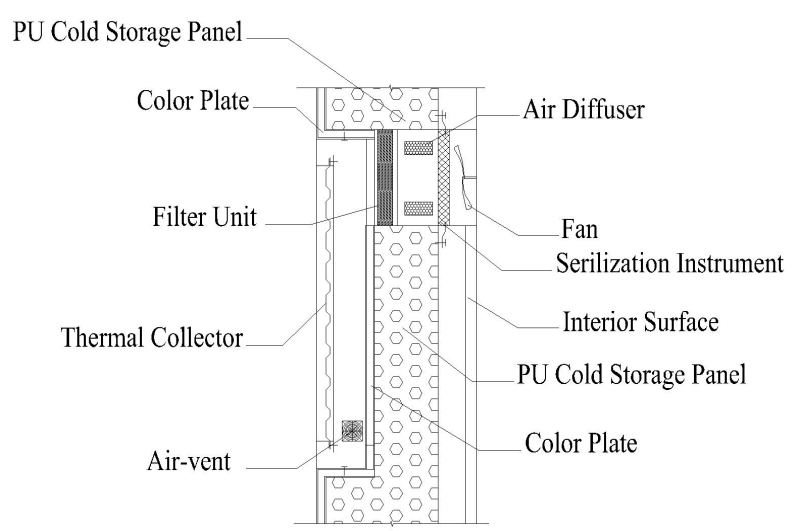

Figure 8. Structure of fresh air system.

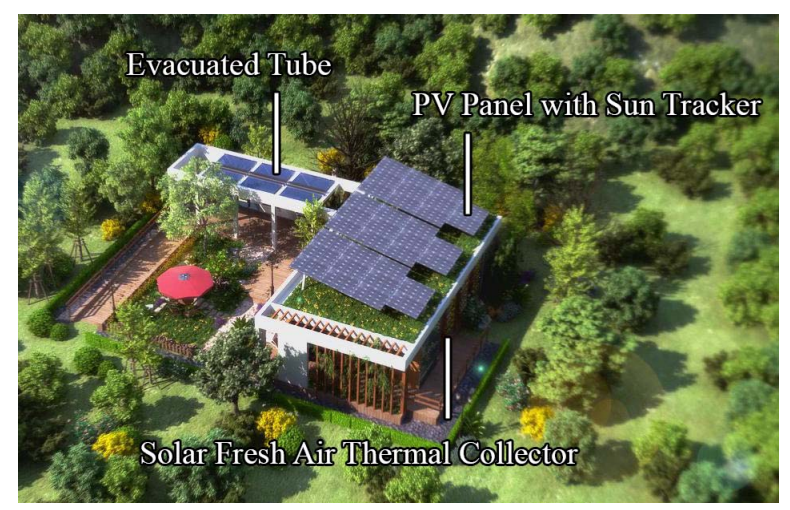

Figure 9. Solar energy technologies. 


\section{Industrialization and Marketization}

SD competition is a stage for solar energy technologies utilized in residential buildings. [4] For this reason, industrialization and marketization are main contents of examination. It is required to design the building with modulus and construct it with industrialized methods. These strategies will offer more attractive buildings to clients.

\subsection{Modularization}

The main building of I-Magic Cube has two parts: exchange room and subsidiary rooms include kitchen, bathroom etc. Shandong Jianzhu University worked closely with construction industry, designing highly prefabricated and modularized Frame CAD steel system in order to product primary building space. Integrated kitchen and bathroom are installed in the house to shorten field construction time.

\subsection{Informatization}

To simulate whole process of building construction, Revit was used to analysis the house. Utilization of Building Information Model facilitates coordinate of all majors and engineering management. It makes positive contribution to reduce negative construction impact on environment.

\subsection{Variability}

Building adopting FrameCAD system could be built up to 3 stories at most. Therefore, the house can be expensed vertically according to actual demand. Moreover, I-Magic Cube selects various reconfigurable furnitures such as wall beds and lifted coffee tables.

\subsection{Economic Feasibility}

I-Magic Cube is designed for a single family while visiting tourism resort districts, as well as for fieldworkers while working in desert areas. Although high-tech productions are more expensive, operation costs of the zero energy house is not high. The house is economically feasible. In addition, the building's structural system is so flexible that it is able to be made to order. According to different customs' personalized requirements, its wall decoration panels, sun louvers and interior establishments could be easily changed.

\section{Conclusions}

I-Magic Cube epitomizes social, economic and environmental challenges zero energy solar house faces in the future development and provides creative solutions. The project plays a good role in the field of architecture together with solar energy technology and popularizes achievements of solar house.

\section{Acknowledgements}

This work was financially supported by the Natural Science Foundation of China (51078223).

\section{REFERENCES}

[1] X. Q. Yang and Hui, “Architectural Technology Strategies of Zero Energy Solar House - Taking Solar Decathlon for Example,” Architectural Journal, No. 8, 2001, pp. 97-102.

[2] R. M. J. Bokel, "The Effect of Window Position and Window Size on the Energy Demand for Heating, Cooling and Electric Lighting,” Proceedings: Building Simulation, 2007, pp. 117-121.

[3] D. Kolokotsa, "A Roadmap towards Intelligent Net Zero-and Positive-Energy Buildings,” Solar Energy, 2010.

[4] A. Walker, D. Renee and S. Bilo, “Advances in solar buildings, Journal of Solar Energy Engineering, Vol. 125, No. 8, 2003, pp. 242-243. 